\title{
UN SONETO DE LOPE (DUERME EL SOL DE BELISA EN NOCHE ESCURA), SUPUESTAMENTE ENVILECIDO, Y SU FUENTE
}

\author{
IGNACIO ARELLANO \\ GRISO (Universidad de Navarra)
}

Aunque las Rimas humanas y divinas del licenciado Tomé de Burguillos se suelen considerar por muchos estudiosos como ejemplo de la poesía sencilla cultivada por Lope frente a la oscuridad culterana, la verdad es que pocas obras de la literatura española encierran tantas dificultades de comprensión, tantos juegos de ingenio y tantos guiños al lector malicioso.

A las muchas dificultades que los poemas de Burguillos presentan al lector, los críticos han añadido alguna que otra, generalmente por no comprender (o no querer comprender) algunos aspectos de la estética del Siglo de Oro en general y de la estética de las Rimas humanas y divinas en particular.

Una de estas dificultades inventadas por los críticos y editores de la poesía de Lope, en este caso originada en un breve artículo de Entrambasaguas, es la que atañe al soneto dedicado «Al retrato de una dama después de muerta», que suele situarse - abusivamente a mi juicio - en la circunstancia de la muerte de Isabel de Urbina, primera mujer de Lope, lo cual impide ya, como se verá enseguida, la recta comprensión del poema ${ }^{1}$ :

Duerme el sol de Belisa en noche escura

y Evandro, su marido, con estraño

dolor pide a Felipe de Liaño

\footnotetext{
1 Propongo mi puntuación. El texto procede de la edición de Rimas humanas y divinas del licenciado Tomé de Burguillos de 1634 (Madrid, Imprenta del Reino). Manejo para el comentario las ediciones de Antonio Carreño, Salamanca, Almar, 2002; Juan Manuel Rozas y Cañas Murillo, Madrid, Castalia, 2005; y Macarena Cuiñas Gómez, Madrid, Cátedra, 2008. Este soneto lleva en las ediciones modernas el número 149, menos en Carreño, que numera dos poemas preliminares, con lo cual este soneto es el 151. No marco gráficamente la diéresis del v. 3 en Liaño; es una licencia métrica usual de la que no hace falta advertir al lector.
} 
retrate, aunque sin alma, su figura.

Felipe restituye a su hermosura

la muerta vida con tan raro engaño

que pensando negar el desengaño

la vista de los ojos se perjura.

Tú dices que mejor fuera olvidalla,

Otavio, pues ya queda helada y fría,

que no dejar espejo en que miralla,

y yo digo, con paz de tu porfía,

que tuvo muy buen gusto en retratalla

al tiempo que mejor le parecía.

Es sabido que Lope traslada muchos elementos autobiográficos a su poesía, y que se asoma a veces en sus versos bajo el nombre de Belardo, mientras que Belisa se asigna en ocasiones a Isabel de Urbina, la primera mujer del poeta. Esta impregnación biográfica de la obra poética lleva a menudo a muchos estudiosos a identificar mecánicamente cualquier personaje que se llame Belardo con Lope, a asociar todas las Elenas de sus versos inmediatamente con Elena Osorio, y a asegurar que todas las Belisas son Isabel de Urbina. Semejantes identificaciones automáticas sirven de muy poco, a no ser para desorientar más veces de las que ayudan. El examen del contexto será necesario para suponer una determinada alusión biográfica. No siempre Belisa podrá ser Isabel de Urbina.

En el soneto que estamos considerando, Entrambasaguas inicia la senda errada que luego seguirán otros. En el breve artículo que dedica al «Envilecimiento de un soneto de Lope de Vega» ${ }^{2}$ denuncia el tipo de lectura que algunos inatentos han hecho del texto. Dada la corta extensión de su comentario se puede resumir con cierto detenimiento.

Para empezar da por evidente que el soneto se dedica a un retrato real encargado por Lope mismo en el momento de la muerte de Isabel de Urbina, lo que le obliga a colocarlo en la categoría de los poemas líricos, elegiacos, serios y emocionados, so pena de hacer de Lope un monstruo sin corazón capaz de bromear sobre la muerte reciente de su esposa:

Cuando murió la primera mujer de Lope, Isabel de Urbina o Alderete, la dulce Belisa de sus versos, hizo el poeta - en su primer arrebato de dolor remordido, tan agudo como rápido en aquella superficial y excitable sensibilidad suya - que el pintor montañés Felipe de Liaño, coterráneo y gran amigo del Fénix, retratase a la muerta como fue en vida, devolviéndole con su arte lo que perdió.

Todos los detalles evocados por la imaginación del glosador carecen de valor crítico: la dulzura de Belisa, el arrebato de dolor remordido, la sensibilidad superficial del poeta... en nada contribuyen a la inteligencia del soneto.

\footnotetext{
${ }^{2}$ Joaquín de Entrambasaguas, «Envilecimiento de un soneto de Lope de Vega», Correo erudito, noviembre, 1941, págs. 81-82.
} 
La que se ofrece en este análisis es una primera interpretación que se apoya únicamente en el nombre de Belisa, y en el detalle de la amistad de Lope con el pintor Felipe Liaño, que ciertamente podía hacer verosímil el encargo de un retrato semejante. Pero que fuera verosímil no significa que el poema se refiera a una circunstancia como la descrita por Entrambasaguas, que resultaría incompatible con el último terceto.

En efecto, una vez aceptado el punto de partida todo el poema ha de ser juzgado sobre esa falsilla y no hay más remedio que forzar el segundo terceto para que encaje. Entrambasaguas pondera entonces la «sutil delicadeza del tema», que responde en el fondo «al sentir renaciente de exaltación de la vida frente a la muerte, subvertiendo un tema predilecto de la poesía medieval». Evandro, que sería «el propio Lope» ${ }^{3}$ quiere borrar la imagen de la muerte «con la presencia de la vida en el retrato de Belisa, pintado por Liaño, para no recordar su cuerpo helado y frío».

Y ahora viene el problema. Encuentra Entrambasaguas en la Floresta española de Francisco Asensio un cuentecillo burlesco «cuya relación con el soneto de Lope es indudable»:

Acabó sus días una malcasada; y como su marido la hiciere retratar muerta, dijeron algunos que se maravillaban de aquella ternura, y que era señal de haberla querido mucho. Respondió otro: Antes la hizo retratar el día que mejor le pareció.

El chiste final del soneto de Lope (evidentemente el mismo que aparece en la Floresta de Asensio) resulta invisible para el empeño elegiaco de Entrambasaguas, quien se explica la deriva satírica imaginando a un supuesto lector anónimo que no entendió el terceto y que elaboró una interpretación envilecida, que luego recogió Asensio en su Floresta. Tal envilecimiento fue posible porque ese lector ignoró «bastantes cosas del original — que no la hizo retratar muerta sino viva, y que precisamente era con vida como mejor le parecía y no habiéndola perdido, lo cual impide el chiste - y por completo su hondo sentido poético, que picarescamente trocó en un cruel e ingenioso - ¿por qué negarlo? - juego de ideas; pero en cambio, vacías de su primitivo sentir, reprodujo exactamente las mismas palabras de los versos de Lope». Por esas razones y «por no haber hallado hasta ahora una fuente común, me atrevo a relacionar tan diversos empleos de unas mismas palabras».

\footnotetext{
${ }^{3}$ Apunta Entrambasaguas: «La identificación de este nombre poético de Lope, que aparece en algunas de sus comedias no ofrece dudas por el texto. Su significado posible ya presenta más. ¿Cabría pensar en una caprichosa expresión «del hombre de Eva», del «eterno femenino»? Me parece algo aventurado, pero muy sugestivo» (Entrambasaguas, «Envilecimiento...», art. cit., págs. 81-82, nota 2). A mí ni la interpretación del nombre ni la identificación me parecen posibles, ni sugestivas ni pertinentes en el poema (insisto: en el poema; no entro a tratar los nombres poéticos de Lope ni la construcción de sus máscaras poéticas a lo largo de su vida y obra).
} 
Meras ilusiones críticas de Entrambasaguas. El chiste de la Floresta de Asensio coincide exactamente con el del soneto de Lope, y en ambos textos tiene igual sentido. No hay vaciamiento del primitivo sentir, ni envilecimiento — si lo hay está en el mismo Lope-, y ciertamente existe una fuente común, que hace pensar en otro «estema» para las filiaciones del cuentecillo, como diré enseguida.

Pero antes conviene revisar las anotaciones de los editores de Burguillos. Ninguno de ellos repara en el chiste final: arrastrados por la identificación de Belisa con Isabel de Urbina, se mantienen en el territorio de la seriedad y la sincera emoción correspondientes a una circunstancia como la muerte de la esposa del poeta.

Carreño solo apunta:

La muerte queda aquí emblematizada en el espacio del retrato de Belisa. Este soneto, a la par con la canción «Ya, pues, todo el mundo mis pasiones» es de las composiciones más tempranas. El soneto se escribe probablemente con motivo de la muerte de Isabel de Urbina, la primera esposa de Lope, que tuvo lugar en Alba de Tormes en 1594.

Rozas y Cañas Murillo le dedican un comentario algo más extenso pero la mayor parte del mismo reproduce fragmentos del artículo de Entrambasaguas que ya se han citado. Consideran posible que se trate de un poema de vejez, inspirado por el retrato de Liaño, en el que Lope pudo reparar muchos años después de la muerte de Isabel, y en todo caso lo califican de «sentida elegía».

Cuiñas Gómez, insiste en la identificación de Belisa con Isabel de Urbina, da noticias del pintor Liaño, y no dice nada del segundo terceto, ni del chiste.

Basta revisar el poema para advertir que si las tres primeras estrofas del poema pueden considerarse serias, elegiacas, o, en otra vía, un elogio amistoso del pintor Felipe Liaño, autor supuesto del retrato de la tal dama ${ }^{4}$, el comentario del locutor en el segundo terceto acaba con el tono anterior: cuando mejor le parecía su mujer era muerta, ciertamente. Esto es lo que dice el poema, diga lo que dijere Entrambasaguas.

El título se refiere a la pintura «después de muerta», no «viva» — como forzando el texto asegura Entrambasaguas- Si se tratara de lo que afirma el estudioso el título podría haber sido mejor «Encomienda al pintor que con sus pinceles resucite los colores de la dama cuando vivía» o algo parecido ${ }^{5}$. También olvida la estructura narrativa y el diálogo implícito que contrasta dos actitudes antitéticas: Burguillos cuenta la muerte de Belisa, y el deseo de su ma-

\footnotetext{
${ }^{4}$ Esa cualidad bastante seria de las primeras estrofas ha contribuido a la lectura que considero errónea del soneto, ejemplo de fusión jocoseria típica de Burguillos.

${ }^{5}$ Claro que el título podría estar errado, pero en este caso responde perfectamente al texto del soneto.
} 
rido Evandro de hacerla retratar después de muerta, pidiéndole a Liaño que retrate su figura «aunque sin alma». No le pide, pues, que la retrate viva: está resignado Evandro a tener un retrato de la figura muerta de Belisa, sin su alma. Es la habilidad extraordinaria del pintor, ponderada en el segundo cuarteto, la que consigue un retrato que parece ser de una dama viva, de tal modo que engaña a los ojos.

Entra entonces un interlocutor de Burguillos, Otavio, quien argumenta que sería mejor olvidar a la dama, ya que la muerte no tiene remedio, y es mejor el olvido que conservar un espejo que recuerde a la muerta todos los días. Y la respuesta de Burguillos es chistosa, y apela a un cuentecillo misógino previo, no original de Lope: «tuvo buen gusto en hacerla retratar muerta pues era así como mejor le parecía».

Nótese que la antítesis que el texto establece entre la actitud de Otavio y la del locutor Burguillos (con paz de tu porfía «perdona si te llevo la contraria») solo es comprensible dando al segundo terceto el sentido jocoso. Si ambos interlocutores estuvieran situados en un tono serio no se podría hacer compatible la calificación de «helada y fría» (v. 10) con el sentido que Entrambasaguas da «al tiempo que mejor le parecía» ('viva, colorida, hermosa'), pues el locutor Burguillos no niega en ningún momento la frialdad de la muerte.

Se ha visto cómo la crítica que se ocupa del soneto sugiere o afirma que la anécdota de Asensio reelabora en sentido burlesco un texto lopiano serio, cosa nada verosímil. La citada Floresta de Asensio, concebida como continuidad de la de Melchor de Santa Cruz, no se recoge en el siglo XVII como señalan Entrambasaguas y Rozas-Cañas Murillo; es compilación del XVIII y aparece en 1730 y 1731, en dos partes («segunda» y «tercera» después de la «primera» que sería la Floresta española de Santa Cruz).

Pero esto no sería obstáculo para pensar en que la formulación del cuentecillo de la mal casada retratada lo hubiera tomado Asensio del soneto de Lope (cosa que no creo). La principal dificultad para aceptar las sugerencias citadas radica en que el cuentecillo satírico es anterior, y Lope lo toma ya de su fuente, que es la misma que sirve a Asensio.

Por tanto no estamos ante un envilecimiento de un texto supuestamente «serio y elegiaco» (el de Lope), vuelto a lo burlón por un compilador de facecias (un lector que lo altera para ser recogido luego por Asensio), sino ante la aplicación de una facecia conocida, cuya dimensión satírica y misógina es imposible desactivar.

Lope sin duda conoce bien los materiales que maneja, y si ha colocado este final es para darle un tono satírico y burlesco al poema completo, que ni puede evocar a la esposa muerta ni desde luego es una sentida elegía por ella, sino un ejercicio de mixtura jocoseria muy abundantemente representado en la colección de Burguillos. 
El cuentecillo, en conclusión, es el apotegma 72 de Juan Rufo, sin duda la fuente de Lope y también la fuente directa de Asensio 6 :

Acabó sus días una malcasada; y como su marido la hiciese retratar muerta, dijeron unos hombres que se maravillaban de aquella ternura, y que era señal de habella querido mucho. Respondió: Antes la hizo retratar el día que mejor le pareció.

Nótese que el texto de Rufo está repetido literalmente por Asensio, lo que evidencia el origen de este último. Semejante procedencia directa es muy lógica: un compilador de facecias no necesita buscar en un soneto de Lope (a través de la alteración de un lector ignorante) un cuentecillo que encuentra en otros repertorios especializados como el de Juan Rufo. Está demostrado que Asensio recurrió a Las seiscientas apotegmas sistemáticamente, y que de Rufo toma el cuento. Alberto Blecua recoge una tabla completa de los textos que Asensio toma de Rufo ${ }^{7}$. Este es, sin duda, la fuente común de Lope y Asensio. Se puede añadir como dato para la difusión de los apotegmas de Rufo este soneto de Lope.

Nada de sentida elegía personal y autobiográfica. Ejercicio de ingeniosa intertextualidad, mezcla de imágenes y motivos líricos con bromas y facecias. El lector del Burguillos tiene que revestirse de la misma flexibilidad que la estética conceptista le propone, si no quiere extraviarse por los caminos de las interpretaciones textuales injustificadas.

6 Juan Rufo, Las seiscientas apotegmas, Alberto Blecua, ed., Madrid, Espasa Calpe, 1972, pág. 37. Este libro de Rufo se publica en Toledo, 1596, es decir, mucho antes que el Burguillos. Pudiera también haber recogido Lope este chiste de versiones orales extendidas a partir de Rufo, pero me parece que se puede establecer con seguridad que Lope manejó el libro de Rufo, cuyo romance de los Comendadores de Córdoba —inserto en Las seiscientas apotegmas_, por ejemplo, debió de servirle de fuente, al menos parcial, para su comedia del mismo título (aunque tenía a su alcance otras versiones del suceso de los comendadores). Sea como fuere recordaré que otra versión del cuentecillo aparece en la recopilación (entre 1619 y 1624) de los cuentos de Juan de Arguijo, conservada manuscrita en tiempos de Lope: «Muriosele a uno su mujer, con quien no había tenido, viviendo, un día de paz. Con todo esto el día de su muerte a gran priesa hizo que un pintor la retratase. Algunos que sabían lo mal que la quería reían y extrañaban que al tiempo de la muerte la hubiese hecho retratar con tanta ternura y sentimiento. Oyolo uno y dijo: - Hízola retratar en el día que mejor debió parecerle»(Cuentos recogidos por Juan de Arguijo y otros, Beatriz Chenot y Maxime Chevalier, eds., Sevilla, Diputación Provincial, 1979, pág. 95). Una corroboración más del sentido satírico del cuento.

${ }^{7}$ Alberto Blecua, prólogo a Juan Rufo, op. cit., pág. XLV. 